Hermoso, V., Ward, D.P. \& Kennard, M.J. (2013). Prioritizing refugia for freshwater biodiversity conservation in highly seasonal ecosystems. Diversity and Distributions. 19: DOI: $10.1111 /$ ddi.12082

Published version on Journal website available at:

http://onlinelibrary.wiley.com/doi/10.1111/ddi.12082/abstract 


\section{Prioritizing refugia for freshwater biodiversity conservation in highly seasonal ecosystems.}

Virgilio Hermoso, Doug P. Ward and Mark J. Kennard.

Australian Rivers Institute and Tropical Rivers and Coastal Knowledge, National Environmental

Research Program Northern Australia Hub, Griffith University, Nathan, Queensland, 4111, Australia

Corresponding author: Virgilio Hermoso

email: virgilio.hermoso@gmail.com

Tlf: (61) 0437218750

Running title: Freshwater priority refugia

Type of manuscript: Biodiversity Research and Reviews 


\section{Abstract}

2 Aim: Refugia play a key ecological role for the persistence of biodiversity in areas subject to natural

3 or human disturbance, like temporary rivers. Temporary freshwater ecosystems regularly experience dry periods, which constrain the availability of suitable habitats. Current and future threats (e.g. water

5

6

7 extraction and climate change) can exacerbate the negative effects of drying conditions on key refugia. This could compromise the persistence of a large proportion of global freshwater biodiversity, so the identification and protection of refugia seems an urgent task.

\section{Location: Northern Australia.}

Methods: We demonstrate a new approach to identify and prioritise the selection of refugia and apply it to the conservation of freshwater fish biodiversity. We identified refugia using estimates of water residency time derived from satellite imagery and used a systematic approach to prioritise areas that provide all the fish species inhabiting the catchment with access to a minimum number of refugia while maximising the length of stream potentially accessible for recolonisation after the dry period. These priority refugia were locked into a broader systematic conservation plan with area-based targets and direct connectivity. We accounted for current threats during the prioritisation process to ensure degraded areas were avoided, thus maximising the ecological value role of priority refugia.

Results: Priority refugia were located in areas submitted to low threat levels. These areas included lowland reaches, where the incidence of threats was less prominent in our study area and headwaters in good condition. An additional set of 106 planning units $\left(6500 \mathrm{~km}^{2}\right)$ were required to represent $10 \%$ of each species' distribution in the broad conservation plan. A hierarchical management zoning scheme was applied to demonstrate how these key ecological features could be effectively protected from the major threats caused by aquatic invasive species and grazing.

Main conclusions: This new approach to identifying priority refugia and incorporating them into the conservation planning process in a systematic way would help enhance the resilience of freshwater biodiversity in temporary systems. 
26 Keywords: connectivity, conservation planning, drought, Marxan, metapopulation, persistence,

27 recolonisation, satellite imagery, water residency. 
Introduction

The persistence of biodiversity in landscapes impacted by natural or human stressors depends largely on the existence of refugia where conditions are more favourable and allow local populations to survive during unfavourable conditions (Sedell et al., 1990). These refugia maintain populations that serve as sources for recolonisation when favourable conditions are restored (e.g., freshwater fish recolonisation of dry areas after a drought; Bond et al., 2008) or as sources of individuals for exchange with other refugia if unfavourable conditions continue (e.g., individuals exchange between patches of forest in a fragmented landscape; Boulinier et al., 2001). Either situation results in a network of spatially separated populations with varying degrees of temporal connectivity (temporal drought vs. forest fragmentation) sustained over time by a positive balance between local extinctions and recolonisation. This population structure (called metapopulation) is common among freshwater fish in temporary rivers (Driscoll, 2007; Larned et al., 2010). Temporary rivers represent a high proportion of freshwater habitats on Earth (Tooth, 2000) and are considered the most common and hydrologically dynamic of all freshwater ecosystems (Larned et al., 2010). These systems regularly experience dry periods of varying duration and intensity, during which freshwater riverine habitats get constrained to a reduced and disconnected set of pools or are completely desiccated. Despite some aquatic organisms developing desiccation resistant life stages (Jenkins \& Boulton, 2003; Bond et al., 2008), most obligate aquatic species depend on remnant habitats containing water as a refuge to survive during these otherwise natural events (Magoulick \& Kobza, 2003; Arthington et al., 2005; 2010). These populations act as sources of recolonisation after the dry period and play a key role in population growth (Arthington et al., 2005), and the maintenance of the metapopulation (Larned et al., 2010). For this reason, identifying and managing viable habitats during dry periods is vital to ensure the persistence of freshwater biodiversity in temporary rivers (Sheldon et al., 2010), and consequently refugia need to be the target of conservation programs. Despite the extended literature that highlights the role of refugia as key ecological features in temporary rivers (e.g., Labbe \& Fausch, 2000; Magalhaes et al., 2002; Larned et al., 2010), and the 
\& Balcombe, 2011), there are few studies aimed at planning for the conservation of freshwater refugia (but see Nel et al., 2011).

The effective conservation of freshwater biodiversity in refugia and protected areas entails an additional layer of complexity to marine or terrestrial applications, given the extraordinary linear nature of rivers and streams and the role that connectivity plays in these environments (e.g., migrations or propagation of threats along the channel network; Linke et al., 2011; Hermoso et al., 2012a). Due to these special characteristics, freshwater communities apparently protected within reserves can be seriously threatened by processes operating far away that propagate along the river network (Hermoso et al., 2011). For this reason, management for conservation in the freshwater realm cannot be constrained to the protected area (Nel et al., 2007; 2009), but must incorporate the upstream and downstream areas that play an important role in maintaining the biodiversity and the ecological processes on which they depend (e.g., migrations). This would require whole-catchment protection, which is not affordable from a socio-economic point of view (e.g., constrain human uses within protected areas). In order to incorporate these requirements into a more implementable scheme, Abell et al., (2007) proposed a hierarchical approach based on three different management zones. These zones ensure effective protection of biodiversity while making the implementation of conservation actions more flexible by avoiding complete restriction of human uses in some of the hierarchical levels. This schedule is composed of "freshwater focal areas", which are key areas for the protection of freshwater biodiversity, similar to protected areas in terrestrial or marine realms; "critical management zones", as areas that need to be managed to maintain the functionality of a focal area and where uses that do not interfere with the function of this area are allowed; "catchment management zones", link the entire upstream catchment to a critical management zone where human uses are not constrained but best practices (treat waste water disposals, maintain riparian buffers in good condition, or by restricting the use of pesticides) are required. Despite the advances in freshwater conservation planning that account for processes and threats (e.g., Esselman \& Alan, 2011; Hermoso et al., 2011; Linke et al., 2012), most examples focus on the identification of priority areas for conservation to achieve representation. Little attention has been given to making more explicit recommendations concerning options for conservation management to sustain biodiversity within 
priority areas (however, see Nel et al., 2011; Thieme et al., 2007 for some examples on freshwater conservation planning).

Here, we integrate the identification of priority refugia into conservation planning for freshwater fish diversity in a wet-dry tropical savannah catchment in northern Australia (Mitchell River). We use the hierarchical management scheme proposed by Abell et al. (2007) to demonstrate how the key ecological features of priority refugia could be effectively protected. We first identify refugia to represent the 42 fish species inhabiting the catchment, and maximise the potential recolonisation after the dry period. These areas were then incorporated into a broader conservation plan where additional ecological processes were considered by accounting for longitudinal connectivity (similar to Hermoso et al., 2011; 2012a; Linke et al., 2012). We finally integrated the set of priority areas identified into the hierarchical conservation management schedule proposed by Abell et al. (2007) and characterise the magnitude of different threats to inform the management actions that would be required. In order to evaluate the effect of current degradation on the identification of priority refugia we compare the results under two independent scenarios: current condition and reference condition (i.e., the absence of threats).

Methods

Study area

The Mitchell River catchment $\left(71,630 \mathrm{~km}^{2}\right)$ is located in northern Queensland, Australia (Fig. 1). The wet-dry tropical climate of the region is largely controlled by the equatorial southern monsoon. It is strongly seasonal with $>80 \%$ of the annual rainfall occurring between the wet season months of December to March. Mean annual rainfall increases from around $600 \mathrm{~mm}$ in the south to over 1,200 $\mathrm{mm}$ in the northeast and northwest. High mean annual evapotranspiration leads to annual water deficits across the catchment except in the very wettest of years (Ward et al., 2011). Many of the major tributaries are highly intermittent (Kennard et al., 2010b), with flows ceasing for a large proportion of the dry season during which time longitudinal connectivity is lost as streams recede to isolated pools. 
112 The spatial distribution of 42 freshwater fish species inhabiting the Mitchell River catchment (Table

113 1) was sourced from Kennard (2010). This database contained predictions of spatial distributions for

114104 freshwater fish species across northern Australia derived from Multivariate Adaptive Regression

115 Splines models (Leathwick et al., 2005) at a fine scale (average area of predictive units was $3.6 \mathrm{~km}^{2}$ ).

116 The predictive model was built on a data set of 1609 presence only sites plus 115 presence-absence

117 sites and validated using an independent data set of 604 presence-absence sites (see Kennard 2010 and

118 Hermoso et al., 2012a for more details on predictive models). The predicted spatial distribution of

119 each species was translated into a network of planning units for subsequent analyses below. We

120 delineated 2,316 planning units from a 9 second digital elevation model using ARC Hydro for ArcGIS

1219.3 (ESRI, 2002). Each planning unit included the portion of river length between two consecutive

122 nodes or river connections (6.6 km on average) and its contributing area ( $31.2 \mathrm{~km}^{2}$ on average). We

123 translated the information from the predictive models for each of the 42 freshwater fish into the

124 planning units by summing the area where each species was predicted to occur within each planning

125 unit.

\section{Identification of priority freshwater refugia}

We used the planning units previously defined as the spatial framework for the identification of priority refugia. We considered candidate refugia as those planning units that contained semipermanent waterbodies defined as waterbodies that were inundated $>80 \%$ of the time (Hermoso et al., 2012b). Inundation frequency during the dry season was derived from satellite imagery and used to identify the location of potential freshwater refugia. Inundation frequency of water bodies during te dry season was based on a 16 year time series of Landsat 5 and 7 TM imagery captured between July and October from 1991 to 2005 as part of the Queensland Wetland Mapping and Classification program (EPA 2005). This duration of record is appropriate for estimating longer term patterns of discharge variability (Kennard et al., 2010a) and the study period encompassed a range of high a and 
et al., 2010b; CSIRO 2009). A total of 773 (33\%) planning units contained at least one waterbody with semi-permanent water. We reduced the set of candidate refugia to planning units with a semipermanent water surface $>5$ ha (not necessarily forming a single water body, $n=232$ planning units).

We chose this threshold to accommodate the spatial resolution of the satellite imagery used for the demonstration we present here, while finer resolution data could be used whenever available to refine the identification of candidate refugia sites.

We used the software Marxan (Ball et al., 2009) to find a combination of refugia planning units to represent all the species in the most cost-effective way (Figure S1). Marxan uses a heuristic algorithm to try to find a near-optimal combination of planning units where all the species are represented in a minimum required area (conservation target), while accounting for some additional constrains such as cost associated with each planning unit or spatial connectivity. This is done by trying to minimise the objective function in Equation 1, which includes cost of planning units in the solution and other penalties for not achieving the conservation target for all the species (Feature Penalty, weighted by Species' Penalty Factor, SPF). An additional penalty can be specified in the objective function to force the spatial aggregation of planning units included in the solution and to maximise connectivity within priority areas. The weight of this penalty can be controlled by a Connectivity Strength Modifier (CSM).

$$
\text { Objective function }=\sum_{\text {planning units }} \text { Cost }+S P F \sum_{\text {features }} \text { Feature Penalty }+C S M \sum \text { Connectivity Penalty }
$$

Equation 1

Given that refugia would provide source populations for re-colonisation, here we aimed to maximise the distance between planning units in the solution. In this way we aimed to maximise the area that could be potentially recolonised after the dry period from priority refugia. Marxan addresses connectivity by means of a boundary file that is used to calculate the connectivity penalty in Equation 1. This file contains the links between all planning units connected along the river network and an associated penalty that is dependent on the distance between them (Fig. 2). Whenever a planning unit is included in the solution, a penalty value is calculated as the sum of all the failed connections 
(connected planning units that are not included in the solution). For example, if planning unit A and B

were connected, and the solution contains A but not B, then the connectivity penalty would be

considered in Equation 1. Instead of using the connectivity penalty to obtain solutions where planning

units are clustered along the river network (see Hermoso et al., 2011; 2012a), here we aimed to

maximise the extent of disconnection (i.e. stream distance) between planning units in the solution, so the length of stream potentially accessible for recolonisation is maximised. We did this by modifying the direct longitudinal connectivity introduced in Hermoso et al. (2011) that favours the selection of closely connected planning units (Fig. 2). Hermoso et al. (2011) used distance-based penalties, so closer planning units would apply a higher penalty if not selected than far distant ones (connectivity penalty $=1 /$ distance $^{2}$ ). Here we applied the inverse approach, so penalties were still distance-based but connections between far distant planning units would receive a high penalty if missed in the solution, while connections between close planning units would receive a low penalty (connectivity penalty= distance $^{2}$ ). In this way, we wanted to favour the selection of distant unconnected planning units (inverse connectivity in Fig. 2).

To account for differences in recolonisation potential for different species, we adapted conservation targets for each species according to their capacity for mobility. We classified each species as high, intermediate and low mobility using expert criteria (Table 1) and information in Pusey et al. (2004), and set a conservation target of 2, 4 and 16 refugia planning units, respectively. In this way, species with low mobility would be represented in at least 16 refugia planning units, while highly mobile species would be represented in 2 . Note that the basic ecological information required to better inform target setting (e.g., true colonization capacity) was lacking, so the targets used here are implemented to demonstrate the approach. Alternative non-target based methodologies have also been applied to conservation and rehabilitation problems in freshwater ecosystems (e.g., Moilanen et al., 2008; Turak et al., 2011). Since we were interested in identifying areas where each species maintains remnant populations that could serve as recolonisation sources (independent of the area occupied), targets were set in terms of number of presences instead of the area occupied by each species within planning units. This also assisted in achieving the aim of acquiring a disconnected set of refugia. This is because it is difficult to maximise disconnection between source populations if targets are defined in 
terms of area (the same area could be achieved by selecting just one big refugia or multiple small ones).

The survival of freshwater biota in refugia can be compromised by human-related perturbations such that the likelihood of survival will be higher in refugia that are in good condition. To account for the potential negative effects of perturbations, we used an estimate of each planning unit's current condition as an additional penalty in Equation 1, such that planning units in poor condition were avoided. We characterised the incidence of five major threats in the catchment [land uses -measured as the proportion of each planning unit devoted to grazing-, fire frequency -estimated as frequency with which the planning unit was burnt in the period 1997-2008-, flow perturbation -measured as the Flow Disturbance Index described in Stein et al. (2002), aquatic weeds and water-dependent feral animals - four classes of relative incidence; $0=$ absent, $1=$ occasional or localised occurrence, $2=$ common and widespread, and 4= abundant and widespread or cane toad (Buffo marinus), pigs (Sus scrofa) and water buffalo (Bubalus bubalis), see Table S1 for more information] as the penalty following the approach proposed in Linke et al. (2012). We compiled the information on threats from existing datasets (see Table S1 for data sources) and then standardised the values (0-1) to avoid the effect of different magnitudes in the overall average value used as a penalty. Finally, we averaged the values of each threat within each planning unit, to be used as an indicator of the overall degradation status in the analyses. We compared the results obtained from this approach against an ideal scenario where no threats were present in the catchment (referred as reference scenario hereafter, where all planning units had a constant cost of 1). This was done to evaluate the potential constraints to the identification of priority refugia imposed by the current incidence of threats in the study area and their impacts on the total area required.

We estimated the area potentially re-colonisable from priority refugia planning units assuming species with low, intermediate and high mobility capacity would be able to move $10 \mathrm{~km}, 50 \mathrm{~km}$ and $100 \mathrm{~km}$ respectively, both upstream and downstream. These thresholds were based on previous estimates on fish movements from refugia in similar environments (Koehn \& Crook, 2013). Consequently, the comparison between both scenarios should only be taken as an indication of constraints imposed by the current condition to the distribution of priority refugia rather than an accurate estimate of the area 
potentially benefited from recolonisation processes. We used the same CSM (CSM=1.5) in both scenarios, to avoid influence of different connectivity weights in the results.

\section{Integration of priority refugia in a conservation plan}

We used Marxan on the whole set of planning units and species distribution data to identify priority areas for conservation in the Mitchell River catchment under the two alternative condition scenarios described above (Figure S1). In this analysis we addressed longitudinal connectivity to account for key ecological processes in freshwater ecosystems, such as movement requirements of fish, or the propagation of perturbations along the river network as proposed by Hermoso et al. (2011). To ensure the inclusion of priority refugia in the solutions we locked the best solution from the refugia prioritisation for both condition scenarios respectively. So two independent analyses were carried out, one for each scenario described above. Since we considered the whole catchment in this new analysis we redefined targets and aimed to represent at least $10 \%$ of each species' area of occurrence. Given the lack of ecological knowledge to guide more objective conservation target setting we used this value for the sake of demonstration only, as for the previous analysis.

239 To enhance the capacity of the priority areas identified above to protect freshwater biodiversity, we identified management zones following the recommendations in Abell et al. (2007). We included all priority areas identified in the broad conservation plan in Marxan as freshwater focal areas as they were selected to maintain key refugia and protect freshwater biodiversity. All planning units connecting priority refugia were labelled as critical management zones as they are important to ensure connectivity along the catchment and especially among refugia. Finally, we identified all the contributing catchments to each refugia as a catchment management zone to ensure that biodiversity within refugia was not at risk. We also characterised the incidence and intensity of threats within each zone in a post-hoc analysis to inform management practices required to ensure the conservation of biodiversity and processes. Threats were taken from the data previously described to characterise current condition. 
251 Results

252 The number and location of priority refugia planning units was clearly influenced by the constraints

253 imposed by the current condition. All the species achieved the aimed conservation target under the two alternative scenarios we tested (reference and current condition). However, while conservation targets for priority refugia could be achieved by selecting 20 planning units under the reference scenario, 25 planning units were needed under the current condition scenario (Fig. 3a). This increase in the number of planning units did not translate into an increase in the estimated area that could be potentially recolonised after the dry season. Priority refugia planning units were distributed more evenly along the catchment under the reference scenario, which increased the area potentially benefited by recolonisation processes (Fig. 3b). Under the current scenario, priority refugia planning units were mostly located in lowland areas of the Mitchell River catchment (Fig. 3a), where the incidence of threats was less prominent (Fig. 1b), and mainly in headwaters where the negative effect of propagation of threats from upstream areas was null. If the catchment was in reference condition, the area potentially recolonisable from priority refugia would be, on average $19 \%$ higher than from refugia identified to accommodate current condition (Fig. 3b). This difference was also apparent when including priority refugia planning units in a broader conservation plan with area-based targets and direct connectivity. Similar to previous results, $14 \%$ more area was required under the current condition scenario than under the reference scenario $\left(7764.5 \mathrm{~km}^{2}\right.$ and $6692.9 \mathrm{~km}^{2}$ respectively) to achieve the conservation targets under the broad conservation plan. Given the differences in results between both scenarios and the clear influence of condition in shaping conservation plans we selected the best solution under the current condition scenario to identify management zones and characterise the incidence and intensity of threats (Fig. 4). This was because it represents a more realistic approach, since most catchments have some form of threatening processes to freshwater biota (Fig. 1). The main threats affecting freshwater focal areas (planning units in best solution of the broad conservation plan) were non-native aquatic species (cane toad and aquatic weeds) and land transformation (grazing), as more than $60 \%$ of planning units within this zone were intensively affected by these threats (Fig. 5). We identified two main corridors as critical management zones that 
connect all the focal freshwater areas with the mouth of the catchment (Fig. 4). These corridors would allow the exchange of individuals among different refugia during the wet season and their connectivity with the ocean required by some migratory species. The same set of threats affecting freshwater focal areas occurred within critical management zones, although a significant increase in the impact of flow alteration occurred (Fig. 5). Only one catchment management zone was necessary since most of freshwater focal areas were located in the headwaters or fully covered catchments in the other two areas. This zone included all the contributing catchments to the priority refugia located in the middle section of the Mitchell River (Fig. 4). The intensity of the main threats described above was even more acute as almost $80 \%$ of planning units contained in this zone were highly threatened (Fig. 5).

Discussion

The identification and protection of refugia has been highlighted as being of particular importance in freshwater environments that are subject to high seasonal changes in water availability, prone to intermittent flows and habitat fragmentation (Bond et al., 2008; Arthington et al., 2010; Crook et al., 2010). Refugia maintain individuals that can repopulate a wider range of habitats when more favourable conditions are restored after seasonal or prolonged droughts (Larned et al., 2010). Consequently, refugia help sustain freshwater populations (metapopulation) in temporary rivers. Despite the important ecological role that these areas play, aquatic refugia have not been adequately or explicitly addressed in freshwater conservation planning to date. Most efforts have focused on other key ecological processes driven by connectivity (Moilanen et al., 2008; Hermoso et al., 2011; 2012a), or how to mitigate the effect of threats (Linke et al., 2007, Moilanen et al., 2011; Linke et al., 2012). Here, we demonstrate how to prioritise key refugia that are required to sustain freshwater populations in temporary rivers using publicly available satellite data on water residency times. This represents an advance on previous efforts focused on single species (Suski \& Cooke, 2007). By using the principle of complementarity (Kirkpatrick 1983), and a modified version of the connectivity penalty proposed by Hermoso et al. (2011), we identified a minimum combination of refugia planning units that maximised the recolonisation potential when connectivity is re-established after a dry 
period. We adapted the number of refugia in which each species should be represented to accommodate a species' capacity to disperse so that the recolonisation potential could be equally maximised. Further ecological knowledge would be required to determine more accurately a species' mobility and better inform target setting.

There is strong evidence that recolonisation can be highly effective at the catchment scale in temporary freshwater ecosystems when connectivity is re-established. Balcombe et al. (2006) found freshwater fish assemblages to be very similar along a temporary river catchment in Australia (Warrego River) during a period of high connectivity, suggesting efficient dispersal after a dry period when significant dissimilarities in species composition were reported. This hypothesis is further supported by genetic analyses. Carini et al. (2006) found low levels of genetic differentiation among different waterholes within the same catchment in two freshwater fish and an invertebrate species respectively. There are no major natural or artificial barriers that constrain the movement of freshwater biota in the catchment that we used as case study. For this reason we could assume free movements along the catchment after the dry period when estimating the potential area that could benefit from recolonisation. However, in heavily regulated rivers the areas potentially recolonisable from refugia will likely be constrained by artificial barriers to movement and this issue should be considered in prioritisation of refugia (Hermoso \& Clavero, 2011). This constrains the areas potentially recolonisable from refugia and should therefore be accounted for in future applications. For example, refugia located in unregulated catchments or tributaries should be preferentially selected for the benefit they can bring to connectivity between isolated populations.

Despite droughts being natural phenomena in many temporary river systems, the frequency and magnitude of these events is expected to increase in some areas under the effects of climate change (Bates et al., 2008). Global-scaled predictions include a 2-3 fold increase in the frequency of extreme low flows in many areas (Arnell, 2003) and a reduction in mean annual discharge exacerbated by increasing temperatures and evaporation rates. As a consequence of this change, some currently perennial freshwater ecosystems will become non-perennial and the duration and extent of water scarcity in already wet-dry seasonal ecosystems will increase. Under these conditions it is likely that riverine habitats will become increasingly fragmented for longer periods (Morrongiello et al., 2011), 
which could compromise the persistence of freshwater biodiversity in some areas (Vörösmarty et al., 2010). Future persistence of freshwater biodiversity in temporary systems will depend on our capacity to enhance the resilience of these systems to stressful events. This can be achieved by for example, focusing conservation and rehabilitation efforts on key refugia, such as the ones identified here. Given the expected increase in areas affected by these events, the approach that we demonstrate here could be useful not only for temporary rivers but also for a wider set of currently perennial freshwater ecosystems or even beyond the freshwater realm. Alternative criteria could be defined, by using sound ecological knowledge on threats and needs of other species, to identify candidate refugia in other realms (e.g., patches of forest for amphibians). All these potential areas must comply with the basic requisite of refugia, such that habitats support populations that could not live elsewhere in the landscape, and that help enhance the resilience of populations. Furthermore, the benefits of this methodology could be enhanced if reasonable estimates of expected changes in water residency time under climate change were available. However, the precise nature of changes in northern Australia's rainfall and runoff under various climate scenarios has been notoriously difficult to quantify with high certainty (Morrongiello et al., 2011). There was a high uncertainty around these predictions for our study area (predictions of change in runoff ranged from increments of $41 \%$ to reductions of $25 \%$ depending on different scenarios; CSIRO, 2009) so we did not consider them for this work. Climate change is expected to affect not only water availability (Morrongiello et al., 2011). Additional threats to the maintenance of the ecological role of refugia related to climate change that should be considered in the future are the impacts of sea level rise or the effect of rising temperatures on the physiological tolerance of some species (Bond et al., 2008; Morrongiello et al., 2011). The former is especially important in our case as some refugia were located in lowland floodplain areas potentially affected by sea level rise.

Some freshwater biota inhabiting temporary rivers have developed resistant traits to withstand the harsh conditions in drying remnant pools, where physical-chemical conditions and biotic interactions (predation and competition) may produce high mortality rates (Matthews \& Marsh-Matthews, 2003; Arthington \& Balcombe, 2011). Despite these adaptations, the key ecological role of refugia can be seriously compromised by different sources of perturbation (Magoulick \& Kobza, 2003; Bond et al., 
2008; Arthington \& Balcombe, 2011). Among other common threats, freshwater refugia are subject to high water extraction pressure, as they are often the only sources of permanent water in the landscape (Kingsford, 2000). For the same reason these areas are threatened by feral species such as water buffalo or pigs that modify habitat and water quality. The introduction of other aquatic non-native species that compete for the reduced resources available in the refugia or predate on native species is also a common threat (Bond et al., 2008). We addresses these threats during the planning process to try to enhance the likelihood of persistence of freshwater biota in priority refugia by i) using estimates of intensity of different threats to avoid the selection of perturbed areas whenever possible and ii) evaluating the occurrence and intensity of threats within priority areas. The latter should help identify key management actions required to attenuate the impact of threats to freshwater biota in key ecological areas and then enhance the likelihood of persistence of freshwater biota. Despite the fact that we used current conditions as a penalty to selection in the optimization process, the widespread incidence of some threats (e.g., non-native cane toads occurred throughout the catchment) meant that none of the priority areas identified were pristine. For this reason some sort of active management would be required to maintain the key ecological role of priority refugia. In some cases this would require protection/rehabilitation of large portions of the catchment, which is often not an option for its socio-economic impact. To try to accommodate the requirements in freshwater conservation into a more realistic framework and identify management needs we have implemented the hierarchical schedule proposed by Abell et al. (2007) in a post-hoc analysis similar to previous work (e.g., Thieme et al., 2007; Nel et al., 2011) for the sake of demonstration only. Each of the management zones plays a different role in the conservation context (see Abell et al., 2007), so not all the threats would require the same level of attention everywhere. Conversely, management actions should focus on those threats that interfere with the main role of each zone. For example, despite the homogeneous intensity of threats within the different zones, we found that flow alteration was higher in the critical management zone than in other zones. Given the predominant connectivity role that this zone must play, this should be an important target for conservation management (e.g., evaluating and maintaining environmental flows). Since the identification of management zones and actions was done in a post-hoc analysis using the best solution obtained from Marxan, the results presented here 
might not be the most cost-effective solution to tackle conservation in the Mitchell River catchment.

391 We think further work is required to integrate the identification of management zones and actions into the same prioritisation schedule (similar to Moilanen et al., 2011) to ensure cost-effectiveness of conservation efforts. In this sense planning units should be ideally evaluated for their highest potential within the hierarchical management schedule proposed by Abell et al. (2007). For example, when deciding whether a planning unit should be included in the conservation plan as a focal management area some additional aspects apart from its contribution to the achievement of conservation targets need to be considered (e.g., feasibility to be connected to other focal management areas or area and cost of the catchment management zone associated with it). If an alternative planning unit or set of them that contribute similarly towards conservation goals but produce better solutions in terms of critical management zones and catchment management zones, the latter should be selected. In addition, the prioritisation of management actions should also ideally be done in a species-specific fashion (e.g., when evaluating the selection of a planning unit, only appropriate management actions to address the needs of the set of species present in the planning unit should be considered). In this way both, the spatial allocation of management zones and actions would be prioritised in a costeffective way.

\section{Acknowledgements}

We thank J. Stein for providing environmental data and B. Pusey and D. Burrows for assistance with compilation of fish data. We acknowledge the Australian Government Department of Sustainability, Environment, Water, Population and Communities, the National Water Commission, the Tropical Rivers and Coastal Knowledge (TRaCK) Research Hub, the National Environmental Research Program Northern Australia Hub, and the Australian Rivers Institute, Griffith University, for funding this study.

415 Additional Supporting Information may be found in the online version of this article:

416 Figure S1 Flow chart of analyses carried out.

417 Table S1 Sources of data used to characterise threat intensity in the Mitchell River catchment. 
419 Biosketches

420 Virgilio Hermoso is a postdoctoral Research Fellow at the Australian Rivers Institute, Griffith

421 University, Australia. His research interest focuses on the study of threats to the conservation of

422 freshwater biodiversity, especially on the interactive effects of habitat degradation and introduced

423 species, as a way to better inform conservation decision making.

424 Doug Ward is a Senior Research Fellow in the Australian Rivers Institute, Griffith University. He has 425 extensive research experience in the application of remote sensing and GIS techniques to natural and 426 urban environmental problems. He is interested in the application of spatial science and remote

427 sensing technologies for the development of new tools and data for understanding processes in aquatic 428 ecology and fluvial geomorphology.

429 Mark Kennard is a Senior Research Fellow at the Australian Rivers Institute, Griffith University,

430 Australia. His research interests include the ecology of freshwater fish, environmental flow

431 management, river bioassessment and conservation planning for freshwater biodiversity.

432 Author contributions: VH conceived the idea and ran the analyses, VH, DW and MK contributed to

433 the writing of the manuscript, which was led by V.H.

434

435

436

437

438 
440 Abell, R., Allan, J.D. \& Lehner, B. (2007) Unlocking the potential of protected areas for freshwaters. Biological Conservation, 134, 48-63.

Arnell, N.W. (2003) Effects of IPCC SRES emission scenarios on river runoff: a global perspective. Hydrology and Earth Systems Science, 7, 619-641.

Arthington, A.H. \& Balcombe, S.R. (2011) Extreme flow variability and the 'boom and bust' ecology of fish in arid-zone floodplain rivers: a case history with implications for environmental flows, conservation and management. Ecohydrology, 4, 708-720.

Arthington, A.H., Balcombe, S.R., Wilson, G.A., Thoms, M.C. \& Marshall, J. (2005) Spatial and temporal variation in fish assemblage structure in isolated waterholes during the 2001 dry season of an aridzone river, Cooper Creek, Australia. Marine and Freshwater Research, 56, 2535.

Arthington, A.H., Olden, J.D., Balcombe, S.R. \& Thoms M.C. (2010) Multi-scale environmental factors explain fish losses and refuge quality in drying waterholes of Cooper Creek, an Australian arid-zone river. Marine and Freshwater Research, 61, 842-856.

Balcombe, S.R., Arthington, A.H., Foster, N.D., Thoms, M.C., Wilson, G.C. \& Bunn, S.E. (2006) Fish assemblages of an Australian dryland river: abundance, assemblage structure and recruitment patterns in the Warrego River, Murray-Darling Basin. Marine and Freshwater Research, 57, 619-633.

Balcombe, S.R., Bunn, S.E., McKenzie-Smith, F.J. \& Davies, P.E. (2005) Variability of fish diets between dry and flood periods in an arid zone floodplain river. Journal of Fish Biology, 67, $1552-1567$.

Ball, I.R., Possingham, H.P. \& Watts, M. (2009) MARXAN and relatives: software for spatial conservation prioritisation. Spatial conservation prioritisation: quantitative methods and computational tools (ed. by A. Moilanen, K.A. Wilson and H.P. Possingham), pp. 185-195. Oxford University Press, Oxford.

Bates, B.C., Kundzewicz, Z.W., Wu, S. \& Palutikof J.P. (2008) Climate Change and Water. Technical Paper of the Intergovernmental Panel on Climate Change. IPCC Secretariat: Geneva. 
Bond, N.R., Lake, P.S. \& Arthington, A.H. (2008) The impacts of drought on freshwater ecosystems: an Australian perspective. Hydrobiologia, 600, 3-16.

Boulinier, T., Nichols, J.D., Hines, J.E., Sauer, J.R., Flather, C.H., Pollock, K.H. (2001) Forest fragmentation and bird community dynamics: Inference at regional scales. Ecology, 82, 11591169.

Carini, G., Hughes, J.M. \& Bunn, S.E. (2006) The role of waterholes as 'refugia' in sustaining genetic diversity and variation of two freshwater species in dryland river systems (Western Queensland, Australia). Freshwater Biology, 51, 1434-1446.

Crook, D.A., Reich, P., Bond, N.R., McMaster, D., Koehn, J.D. \& Lake, P.S. (2010) Using biological information to support proactive strategies for managing freshwater fish during drought. Marine and Freshwater Research, 61, 379-387.

CSIRO (2009) Water in the Gulf of Carpentaria Drainage Division. A report to the Australian Government from the CSIRO Northern Australia Sustainable Yields Project. CSIRO Water for a Healthy Country Flagship, Australia. 479pp.

Driscoll, D.A. (2007) How to find a metapopulation. Canadian Journal of Zoology, 85, 1031-1048.

EPA. (2005) Wetland Mapping and Classification Methodology - Overall Framework - A Method to Provide Baseline Mapping and Classification for Wetlands in Queensland. D. o. E. a. R. Management. Brisbane, Australia., Queensland Government.

ESRI. (2002) ArcGIS. Environmental Systems Research Institute, Redlands, CA.

Esselman, P.C. \& Allan, J.D. (2011) Application of species distribution models and conservation planning software to the design of a reserve network for the riverine fishes of northeastern Mesoamerica. Freshwater Biology, 56, 71-88.

Graham, R. \& Harris, J.H. (2005) Floodplain Inundation and fish dynamics in the Murray-Darling Basin. Current concepts and future research: a scoping study. Cooperative Research for Freshwater Ecology, Canberra, Australian Capital Territory, 52 pp.

Hermoso, V., Kennard, M.J. \& Linke, S. (2012a) Integrating multi-directional connectivity requirements in systematic conservation planning to prioritise fish and waterbird habitat in freshwater systems. Diversity and Distributions, 18, 448-458. 
Hermoso, V., Linke, S., Prenda, J. \& Possingham, H.P. (2011) Addressing longitudinal connectivity in the systematic conservation planning of fresh waters. Freshwater Biology 56:57-70.

Hermoso, V., \& Clavero, M. (2011) Threatening processes and conservation managementof endemic freshwater fish in the Mediterranean basin: a review. Marine and Freshwater Research, 62 , 244-254.

Hermoso, V., Ward, D.P. and Kennard, M.J. (2012b) Using water residency time to enhance spatiotemporal connectivity for conservation planning in seasonally dynamic freshwater ecosystems. Journal of Applied Ecology,49, 1028-1035.

Jenkins, K.M., and A.J. Boulton. 2007. Detecting impacts and setting restoration targets in arid-zone rivers: Aquatic micro-invertebrate responses to reduced floodplain inundation. Journal of Applied Ecology 44:823-832.

Kennard, M.J. (2010) Identifying high conservation value aquatic ecosystems in northern Australia. Interim Report for the Department of Environment, Water, Heritage and the Arts and the National Water Commission. Tropical Rivers and Coastal Knowledge (TRaCK) Commonwealth Environmental Research Facility, Charles Darwin University, Darwin. ISBN: 978-1-921576-23-2. Available at: http://www.environment.gov.au/water/publications/policyprograms/nawfa-hcvae-trial-report.html (accessed 10 July 2012).

Kennard, M.J., Pusey, B.J., Mackay, S.J., Olden, J.D. \& Marsh, N. (2010a). Quantifying uncertainty in estimation of hydrologic metrics for ecohydrological studies. River Research and Applications. 26, 137-156.

Kennard, M.J., Pusey, B.J., Olden, J.D., Mackay, S.J., Stein, J.L. \& Marsh, N. (2010b) Classification of natural flow regimes in Australia to support environmental flow management. Freshwater Biology, 55, 171-193

Kingsford, R.T. (2000) Protecting rivers in arid regions or pumping them dry? Hydrobiologia, 427, 111.

Kirkpatrick, J.B. (1983) An iterative method for establishing priorities for the selection of nature reserves: an example from Tasmania. Biological Conservation, 25, 127-134. 
Koehn, J.D., \& Crook, D.A. (2013) Movement and Migration. Ecology of Australian Freshwater Fishes (ed. by P.Humphries and K.F.Walker). pp. 105-130. CSIRO Publishing, Melbourne, Australia.

Labbe, T.R. \& Fausch, K.D. (2000) Dynamics of intermittent stream habitat regulate persistence of a threatened fish at multiple scales. Ecological Applications, 6, 1774-1791.

Larned, S.T., Datry, T., Arscott, D.B. \& Tockner, K. (2010) Emerging concepts in temporary-river ecology. Freshwater Biology, 55, 717-738.

Leathwick, J.R., Rowe, D., Richardson, J., Elith, J., \& Hastie, T. (2005) Using multivariate adaptive regression splines to predict the distribution of New Zealand's freshwater diadromous fish. Freshwater Biology, 50, 2034-2052.

Linke, S., Kennard, M.J., Hermoso, V., Olden, J.D., Stein, J. \& Pusey, B.J. (2012) Merging connectivity rules and large-scale condition assessment improves conservation adequacy in a tropical Australian river. Journal of Applied Ecology , 49, 1036-1045.

Linke, S., Pressey, R.L., Bailey, R.C. \& Norris, R.H. (2007) Management options for river conservation planning: condition and conservation re-visited. Freshwater Biology, 52, 918 938.

Linke, S., Turak, E. \& Nel, J. (2011) Freshwater conservation planning: the case for systematic approaches. Freshwater Biology, 56, 6-20.

Magalhães, M.F., Beja, P., Canas, C. \& Collares-Pereira, M.J. (2002) Functional heterogeneity of dryseason fish refugia across a Mediterranean catchment: the role of habitat and predation. Freshwater Biology, 47, 1919-1934.

Magoulick, D.D. \& Kobza, R.M. (2003) The role of refugia for fishes during drought: a review and synthesis. Freshwater Biology, 48, 1186-1198.

Maidment, D.R. (2002) Arc Hydro: GIS for Water Resources. ESRI Press, Redlands, CA.

Matthews, W.J. \& Marsh-Matthews, E. (2003) Effects of drought on fish across axes of space, time and ecological complexity. Freshwater Biology, 48, 1232-1253.

Moilanen, A., Leathwick, J. \& Elith, J. (2008) A method for spatial freshwater conservation prioritization. Freshwater Biology, 53, 577-592. 
Moilanen, A., Leathwick, J.R. \& Quinn, J.M. (2011) Spatial prioritization of conservation management. Conservation Letters, 4, 383-393.

Morrongiello, J.R., Beatty, S.J., Bennett, J.C., Crook, D.A., Ikedife, D.N.E., Kennard, M.J., Kerezsy, A., Lintermans, M., McNeil, D.G., Pusey, B.J. \& Rayner T. (2011) Climate change and its implications for Australia's freshwater fish. Marine and Freshwater Research, 62, 1082-1098.

Nel, J.L., Reyers, B., Roux, D.J., Impson, N.D. \& Cowling, R.M. (2011) Designing a conservation area network that supports the representation and persistence of freshwater biodiversity. Freshwater Biology, 56, 106-124.

Nel, J.L., Roux D.J., Abell, R., Ashton, P.J., Cowling, R.M., Higgins, J.V., Thieme, M. \& Viers, J.H. (2009) Progress and challenges in freshwater conservation planning. Aquatic Conservation: Marine and Freshwater Ecosystems, 19, 474-485.

Nel, J.L., Roux, D.J., Maree, G., Kleynhans, C.J., Moolman, J., Reyers, B., Rouget, M., Cowling, R.M. (2007) Rivers in peril inside and outside protected areas: A systematic approach to conservation assessment of river ecosystems. Diversity and Distributions, 13, 341-352.

Pires D.F., Pires, A.M., Collares-Pereira, M.J. \& Magalhães, M.F. (2010) Variation in fish assemblages across dry-season pools in a Mediterranean stream: effects of pool morphology, physicochemical factors and spatial context. Ecology of Freshwater Fish, 19, 74-86.

Pusey, B.J., Kennard, M.J. \& Arthington, A.H. (2004) Freshwater Fishes of North-Eastern Australia. CSIRO Publishing, Collingwood. 684pp.

Sedell, J.R., Reeves, G.H., Hauer, F.R., Stanford, J.A. \& Hawkins, C.P. (1990) Role of refugia in recovery from disturbances: modern fragmented and disconnected river systems. Environmental Management, 14, 711-724.

Sheldon F., Bunn, S.E., Hughes, J.M., Arthington, A.H., Balcombe, S.R. \& Fellows C.S. (2010) Ecological roles and threats to aquatic refugia in arid landscapes: dryland river waterholes. Marine and Freshwater Research, 61, 885-895.

Suski, C.D. \& Cooke, S.J. (2007) Conservation of aquatic resources through the use of freshwater protected areas: opportunities and challenges. Biodiversity and Conservation, 16, 2015-2029. 
Thieme, M., Lehner, B., Abell, R., Hamilton, S.K., Kellndorfer, J., Powell, G. \& Riveros, J.C. (2007) Freshwater conservation planning in data-poor areas: an example from a remote Amazonian basin (Madre de Dios River, Peru and Bolivia). Biological Conservation, 35, 484-501.

Tooth, S. (2000) Process, form and change in dryland rivers: a review of recent research. Earth Science Reviews, 51, 67-107.

Turak, E., Ferrier, S., Barrett, T., Mesley, E., Drielsma, M., Manion, G., Doyle, G., Stein, J. \& Gordon, G. (2011) Planning for the persistence of freshwater biodiversity: exploring alternative futures using process-based models. Freshwater Biology, 56, 39-56.

Vörösmarty C. J., McIntyre, P.B., Gessner, M. O., Dudgeon, D., Prusevich, A., Green, P., Glidden, S., Bunn, S.E., Sullivan, C.A., Liermann, C.R. \& Davies, P.M. (2010) Global threats to human water security and river biodiversity. Nature, 467, 555-561.

Ward, D., Pusey B., Brooks A., Olley J., Shellberg J., Spencer J., Tews K. (2011) River landscapes and aquatic systems diversity. Aquatic Biodiversity in Northern Australia: Patterns, Threats and Future (ed by B.J. Pusey), pp 5-22. Charles Darwin University Press, Darwin. 
593 Table 1. List of 42 freshwater fish species inhabiting the Mitchell River catchment, northern

594 Australia. The predicted area of occurrence of each species (sourced from Kennard, 2010) and the

595 mobility capacity of each species $(\mathrm{H}=$ high, $\mathrm{M}=$ medium, $\mathrm{L}=$ low $)$ are also shown.

\begin{tabular}{lcc}
\hline Species & Mobility & Area $\left(\mathrm{Km}^{2}\right)$ \\
\hline Scleropages jardinii & $\mathrm{L}$ & 26130.2 \\
Nematalosa erebi & $\mathrm{M}$ & 34153.3 \\
Thryssa scratchleyi & $\mathrm{H}$ & 17161.0 \\
Neoarius berneyi & $\mathrm{M}$ & 21077.0 \\
Neoarius graeffei & $\mathrm{M}$ & 8832.2 \\
Neoarius leptaspis & $\mathrm{M}$ & 10920.3 \\
Neoarius paucus & $\mathrm{M}$ & 45154.8 \\
Anodontiglanis dahli & $\mathrm{H}$ & 22921.2 \\
Neosilurus ater & $\mathrm{H}$ & 32947.6 \\
Neosilurus hyrtlii & $\mathrm{H}$ & 26560.3 \\
Porochilus rendahli & $\mathrm{H}$ & 17874.5 \\
Arramphus sclerolepis & $\mathrm{H}$ & 18386.5 \\
Zenarchopterus spp. & $\mathrm{M}$ & 10130.7 \\
Strongylura krefftii & $\mathrm{M}$ & 25112.6 \\
Craterocephalus stercusmuscarum & $\mathrm{M}$ & 54071.5 \\
Iriatherina werneri & $\mathrm{L}$ & 1639.4 \\
Melanotaenia splendida inornata & $\mathrm{H}$ & 70157.5 \\
Pseudomugil tennellus & $\mathrm{L}$ & 2118.939 \\
Ophisternon spp. & $\mathrm{M}$ & 26898.5 \\
Ambassis sp. & $\mathrm{M}$ & 778.9 \\
Ambassis agrammus & $\mathrm{M}$ & 8789.8 \\
Ambassis macleayi & $\mathrm{M}$ & 51412.0 \\
Denariusa bandata & $\mathrm{L}$ & 11330.0 \\
Lates calcarifer & $\mathrm{H}$ & 22966.9 \\
Amniataba percoides & $\mathrm{H}$ & 64519.0 \\
Hephaestus carbo & $\mathrm{M}$ & 10098.4 \\
Hephaestus fuliginosus & $\mathrm{H}$ & 64041.6 \\
Variicthys lacustris & $\mathrm{L}$ & 365.7 \\
Leiopotherapon unicolor & $\mathrm{H}$ & 65926.9 \\
Scortum ogilbyi & $\mathrm{H}$ & 60007.9 \\
Glossamia aprion & $\mathrm{L}$ & 52607.2 \\
Toxotes chatareus & $\mathrm{M}$ & 45386.6 \\
Glossogobius aureus & $\mathrm{H}$ & 40946.1 \\
Glossogobius giuris & $\mathrm{H}$ & 950.8 \\
Glossogobius sp. 2 & $\mathrm{H}$ & 370.7 \\
Hypseleotris compressa & $\mathrm{H}$ & 14594.7 \\
Mogurnda mogurnda & $\mathrm{H}$ & 64179.9 \\
Oxyeleotris lineolatus & $\mathrm{M}$ & 3218.8 \\
Oxyeleotris selheimi & $\mathrm{M}$ & 12046.5 \\
Synaptura salinarum & $\mathrm{H}$ & 10908.8 \\
Synaptura selheimi & $\mathrm{H}$ & 27689.3 \\
Megalops cyprinoides & $\mathrm{H}$ & \\
Average & & \\
\hline & &
\end{tabular}


597 Figure 1. a) Average area in $\mathrm{km}^{2}$ within each planning unit that retained water $>80 \%$ of the time for

598 the period 1991-2005. This was used to identify candidate refugia planning units $\left(>5 \mathrm{~km}^{2}\right)$. b) Current

599 condition, measured as the average intensity over seven threats (grazing, aquatic weeds, feral buffalos,

600 feral pigs, cane toads, fire frequency and flow alteration). Threat intensities were standardised to a 0-1

601 range prior averaging values across different threats. The inset map shows the location of the Mitchell

602 River catchment (shaded area) in northern Australia.

603 Figure 2. Example of longitudinal direct and inverse connectivity penalties applied in this work. The 604 topology of a stream network delineated in ArcHydro (Maidment, 2002) for ArcGIS 9.3 was used to 605 route connections along the stream network and calculate distances between planning units. The direct 606 penalty applied for a missing connection (e.g., including planning unit 1 but not 2) is calculated as the 607 inverse of the squared distance between planning units $\mathrm{i}$ and $\mathrm{j}\left(\mathrm{d}_{\mathrm{ij}}\right.$ in figure; Hermoso et al.,, 2011). In this way, the penalty for selecting planning unit 1 but not 2 is higher than is selecting planning unit 1 but not 3 . This helps achieve longitudinally connected planning units. Similarly, the inverse connectivity used in the identification of refugia was distance based. In this case the penalty was assessed as the square distance between planning units ( $\mathrm{d}_{\mathrm{ij}}$ in figure), so high penalties would apply if selecting planning unit 1 but not the most distant one (planning unit 3 in the example).

613 Figure 3. a) Location of priority refugia (black) from the set of candidate (grey) under the two 614 alternative scenarios tested (current condition, where threats were used to penalise the selection of perturbed planning units, and reference where no penalties were applied). b) Estimation of potentially re-colonisable areas from the set of priority refugia (10,50 and $100 \mathrm{~km}$ for low, intermediate and high mobility species). Species mobility is specified in Table 1.

618 Figure 4. Spatial distribution of management zones after Abell et al. (2007) for the Mitchell River

619 catchment. Three management zones were described using the best solution from the broad conservation plan under the current condition scenario. Focal freshwater areas contained all planning units in the best solution from Marxan (dark grey) where priority refugia were locked in to force their inclusion ( $\mathrm{n}=132$ planning units in black). Critical management zones included corridors to connect focal freshwater areas ( $\mathrm{n}=299$ planning units in light grey) and Catchment management zones 
624 included all the upstream areas to focal freshwater areas that had not been included in any of the

625 previous zones ( $\mathrm{n}=1189$ planning units in striped shade).

626 Figure 5. Incidence of threats within each management zone. The incidence of threats is showed as

627 the cumulative proportion of the total area within each management zone (Fig. 4) that is submitted to

628 different threat intensities. Common and intense threats are characterised by curves with steep

629 increase from the bottom left corner of the graph indicating a high proportion of planning units

630 affected by high intensity of threat (e.g., grazing or aquatic weeds).

631

632 
634
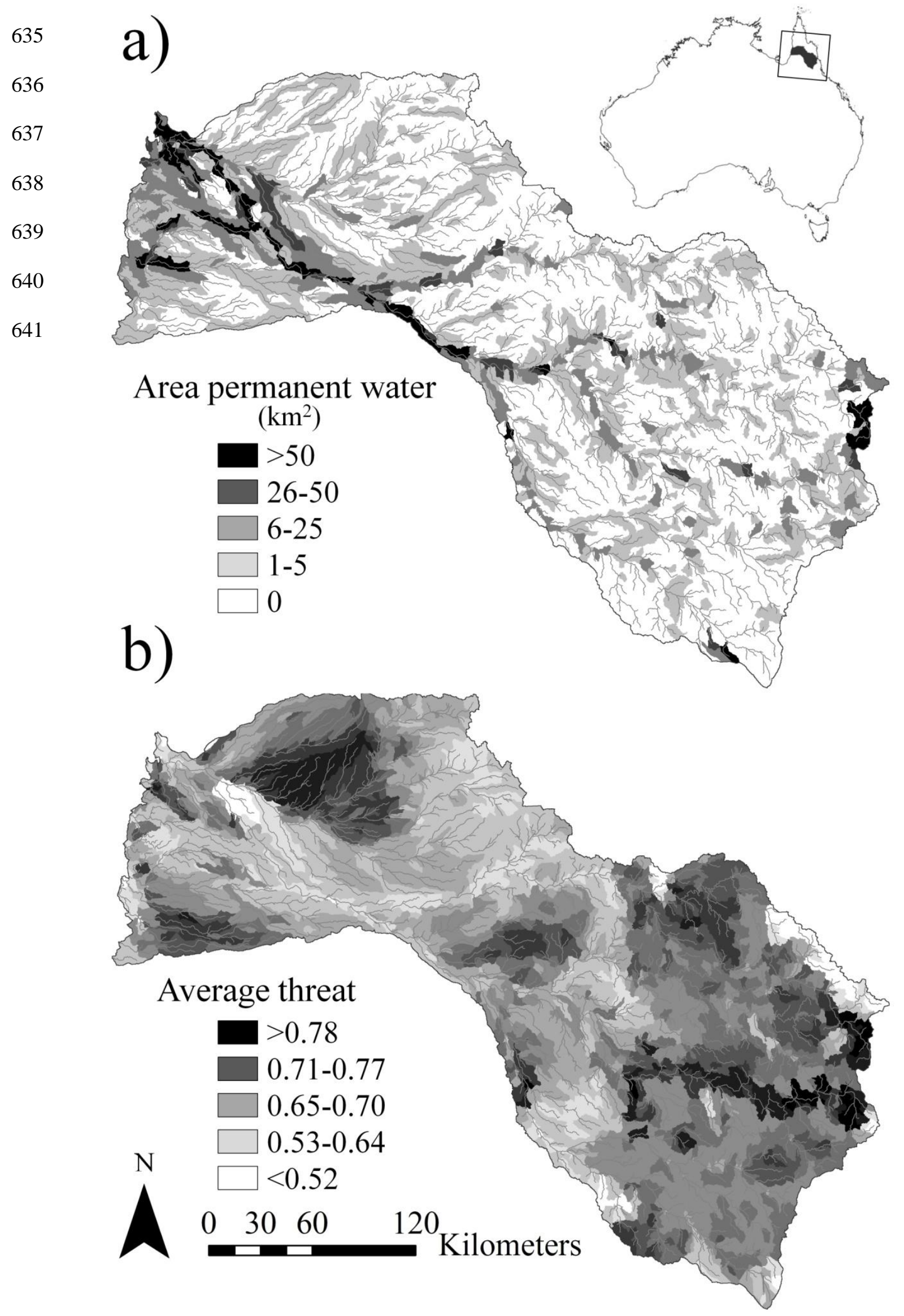
642 Figure 2.

643

644

Direct connectivity

Inverse connectivity
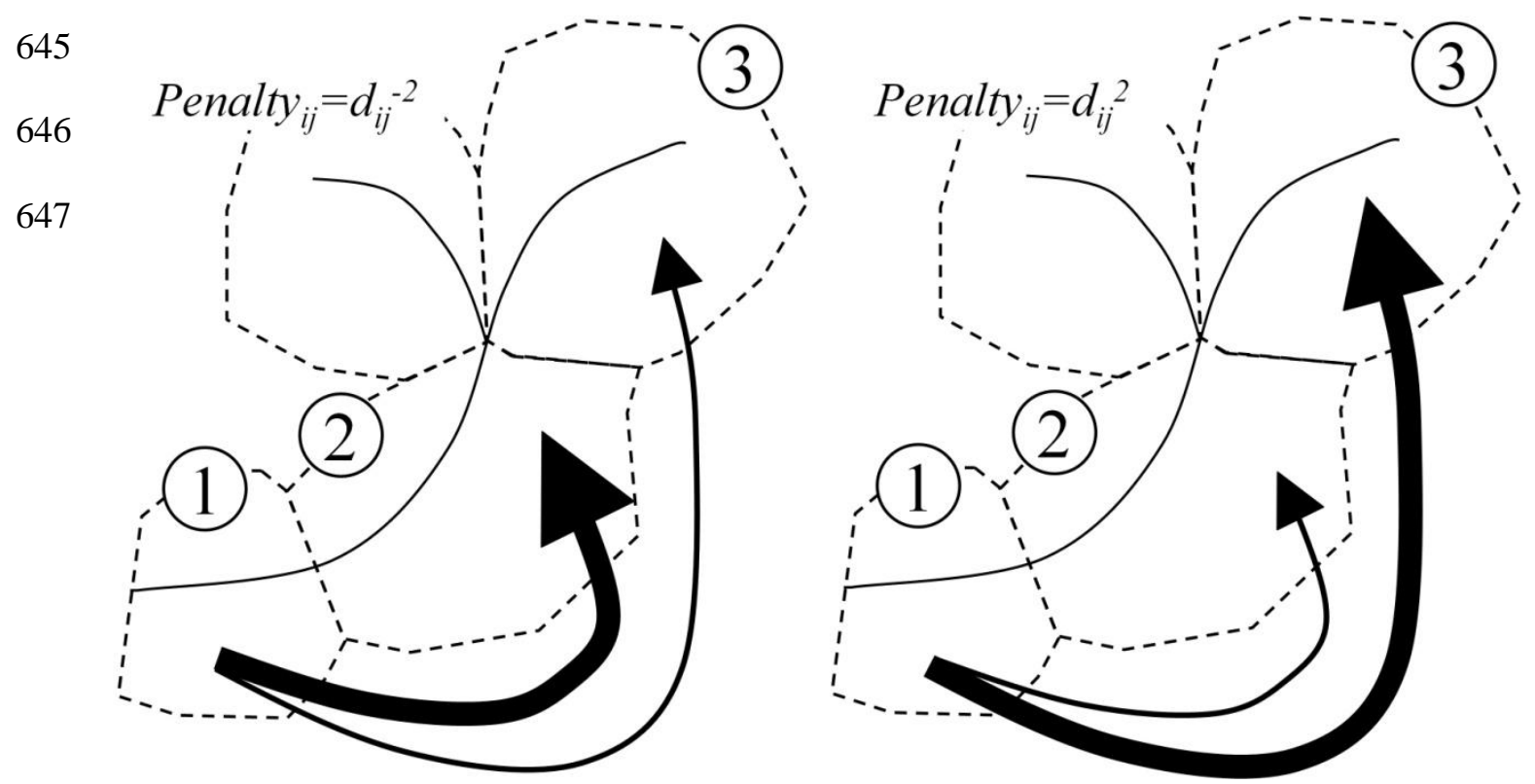
Figure 3.
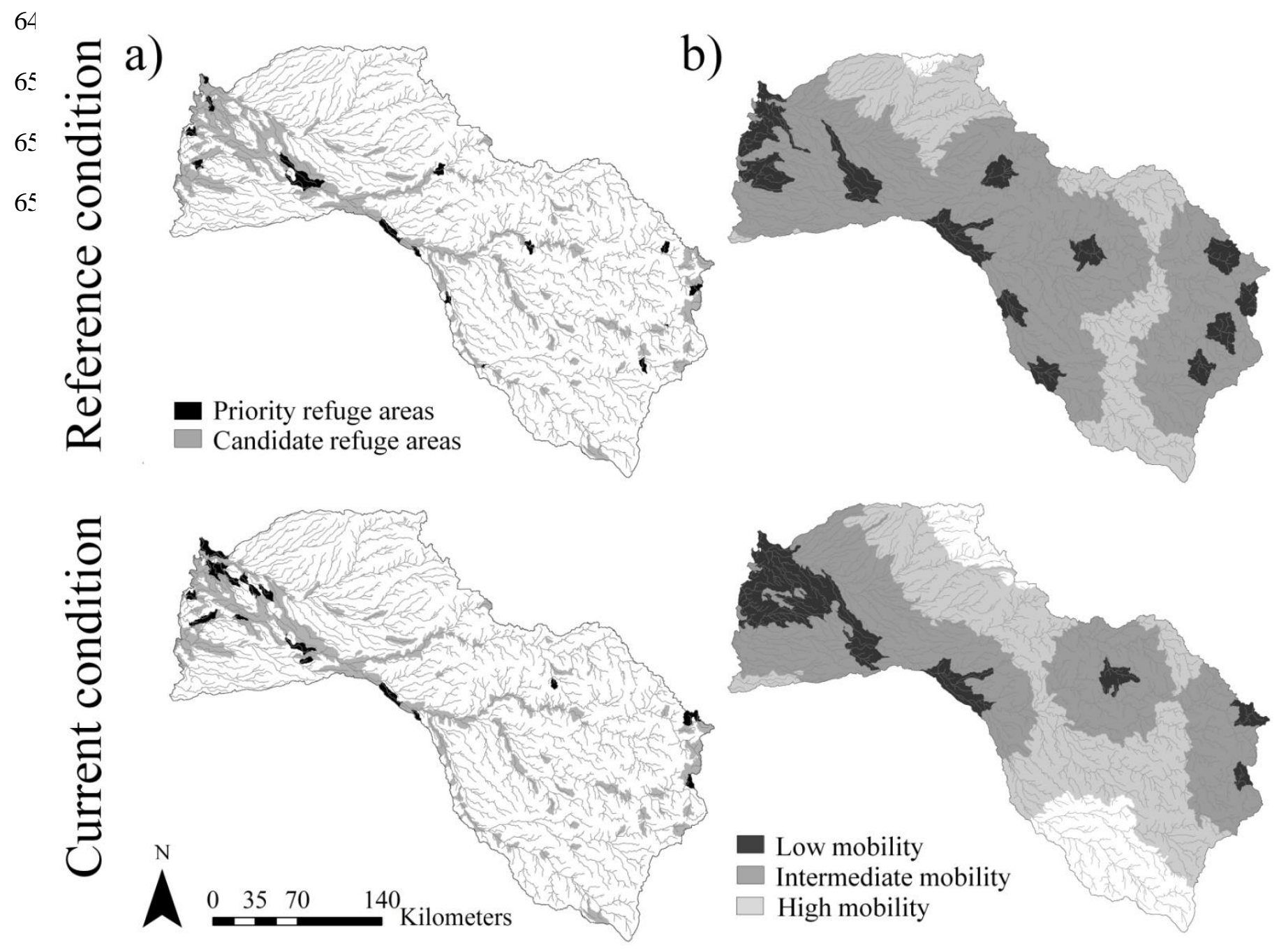
653 Figure 4.

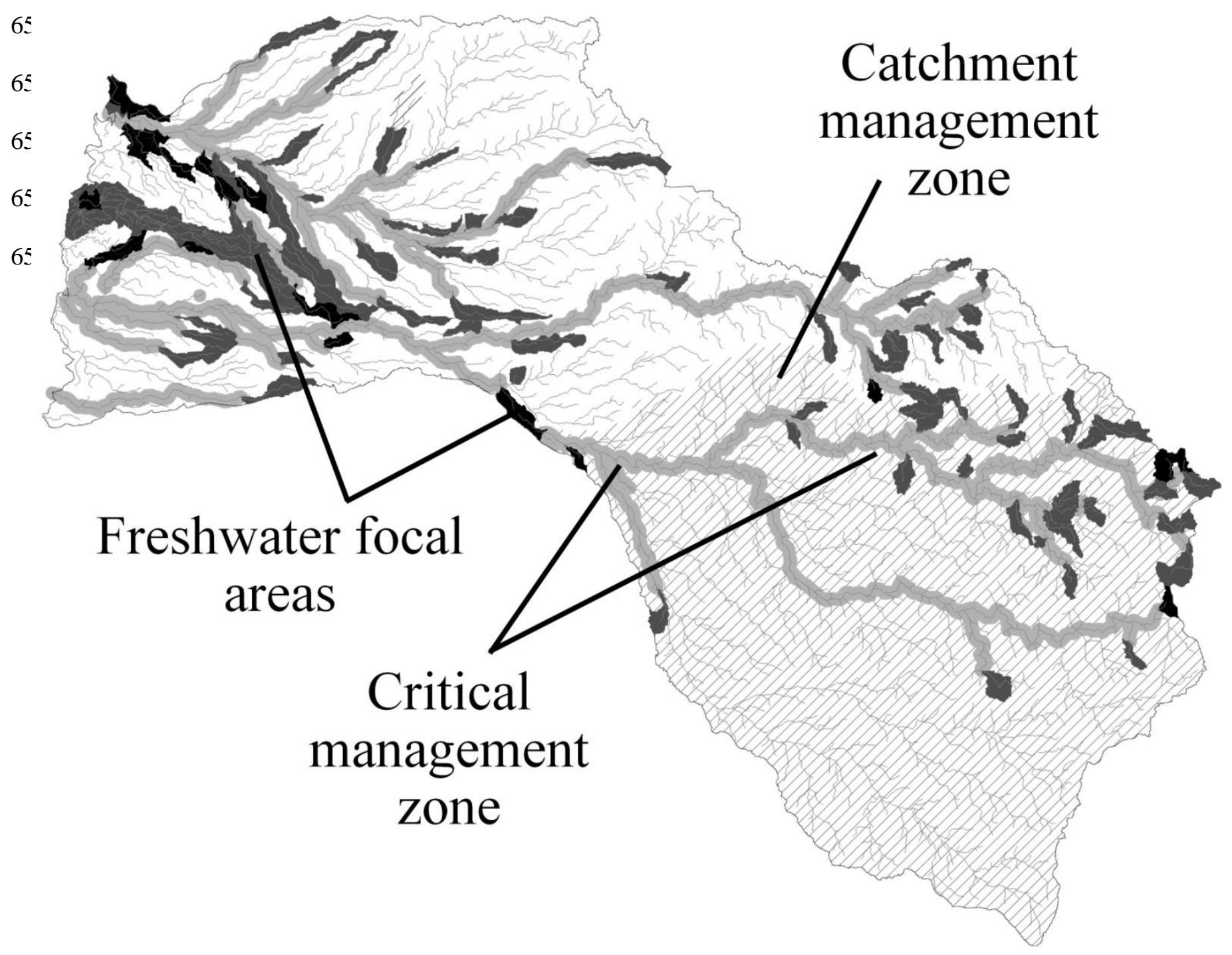


Figure 5.

660

661

662

663

664
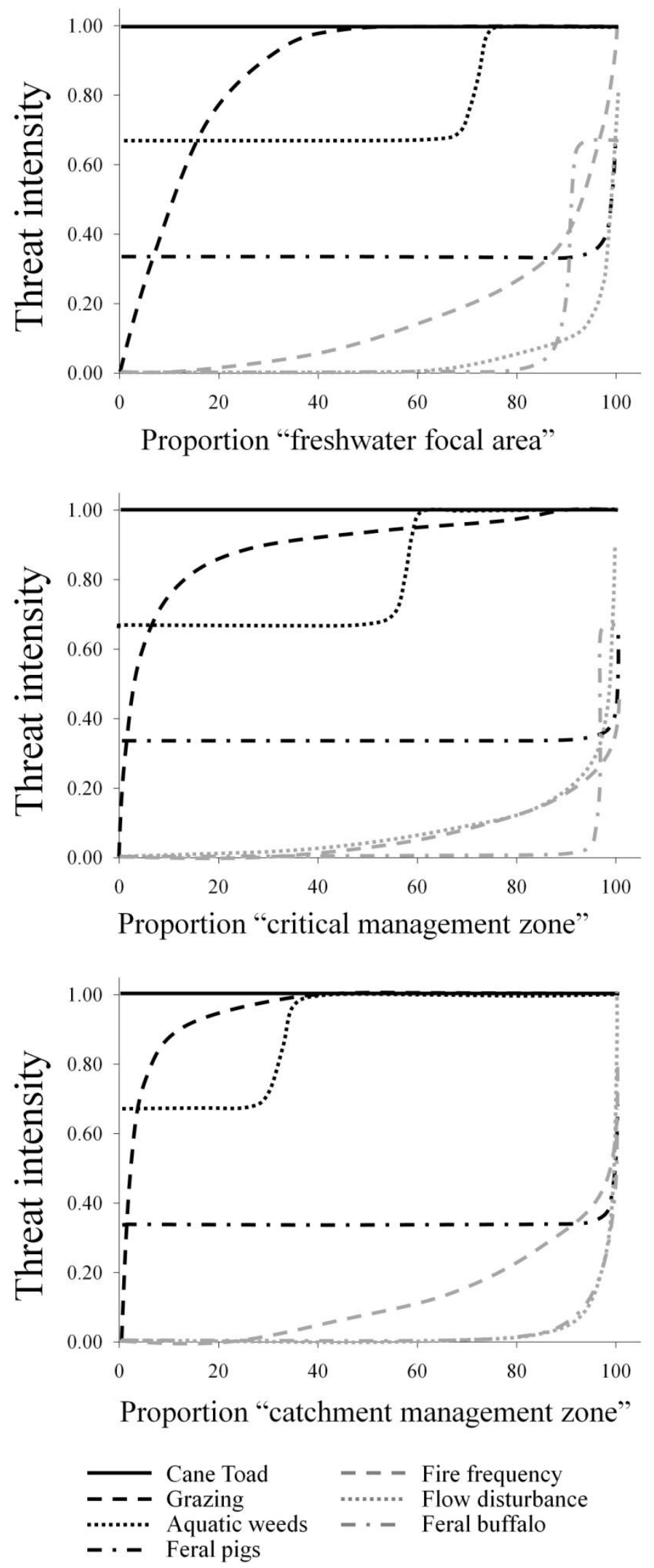